\title{
Long Segmenter Reconstruction of Diffusely Diseased of The Left Anterior Descending Artery Without CAGB
}

\author{
SALIH FEHMI KATIRCIOGLU ${ }^{1}$, Hasan Attila Keskin ${ }^{1}$, Şevket Atasoy ${ }^{1}$, and Avni Dinç ${ }^{1}$ \\ ${ }^{1}$ Ankara Education and Research Hospital
}

May 13, 2020

\begin{abstract}
In this case report we described the results in a patient whose left anterior descending coronary artery (LAD) was totally occluded. We revascularized the patient with diffuse atherosclerosis in LAD only by performing endarterectomy without CABG. We think that this method may be an alternative technique to conventional revascularization in LAD diffuse atherosclerosis

Long Segmenter Reconstruction of Diffusely Diseased of The Left Anterior Descending Artery Without CAGB

Revascularisation of LAD without CAGB

Salih Fehmi Katırcıŏ̆luํㅜ, Hasan Attila Keskin ${ }^{1}$, Şevket Atasoy ${ }^{1}$, Avni Dinç ${ }^{2}$

${ }^{1}$ Department of Cardiovascular Surgery, SBU Ankara Training and Educational Hospital, Ankara, Turkey

${ }^{2}$ Department of Anesthesiology, SBU Ankara Training and Educational Hospital,Ankara, Turkey

Corresponding Author; Hasan Attila Keskin, 1598 Caddesi Kümeevleri Park Sitesi, F1 Blok 22 Numara, Bilkent, 06800, Ankara, TURKEY; attilakeskin@hotmail.com
\end{abstract}

\begin{abstract}
In this case report we described the results in a patient whose left anterior descending coronary artery (LAD) was totally occluded. We revascularized the patient with diffuse atherosclerosis in LAD only by performing endarterectomy without CABG. We think that this method may be an alternative technique to conventional revascularization in LAD diffuse atherosclerosis.
\end{abstract}

\section{KEYWORDS}

Coronary artery disease, LAD endarterectomy

\section{INTRODUCTION}

Coronary bypass grafting is well known surgical treatment method allowing to restore the coronary blood flow. Inadequate revascularization is the most important predictor factor for long-term outcomes in coronary bypass surgery (1). The LAD revascularization is the most important one in coronary vascularization. Coronary endarterectomy was first described by Bailey et al. in 1950 (2). Coronary endarterectomy was been performed on all presence of diffusely diseased coronary arteries that are not suised for distal grafting (3). Due to the deterioration of endothelial integrity after coronary endarterectomy, thrombus may develop in the early period and therefore, surgeons avoid endarterectomy. Acceptable clinical and angiographic results have been published (4).

CASE 
A 58-year-old male patient with LAD diffuse patient had hyperlipidemia and hypertension. Preoperative angiography showed that he had triple-vessel disease with diffusely diseased LAD (Fig 1). In echocardiography (EKO), EF was detected as 60 and PAP $25 \mathrm{mmHg}$ and 2 degrees of tricuspid insufficiency.

In this case report, we will present our LAD endarterectomy. Surgical technique: We performed standard general anesthesia, cardiopulmonary bypass procedure and moderate hypothermia after cold cardioplegic capture. Approximately $10 \mathrm{~cm}$ long endarterectomy was performed on LAD. It was for a dissector to develop

in the plane between the media and atheroma. Mild traction was applied to separate the atherosclerotic plaque with the branches of the coronary artery, the distal and proximal part of the LAD. We were sure no plaque of LAD distal options. Then we applied the same procedure to the proximal part of the LAD. We observed that the proximal atherosclerotic plaque was removed completely. We also observed the rotation of bolus cardioplegia through retrograde cardioplegia. We used saphenous vein for LAD reconstruction (Figure 2). With the traditional cardiopulmonary bypass surgery, individual bypass was applied to the obtuse marginal artery (OM1) and the diagonal artery (D) using saphenous vein graft. LAD proximal antegrade flow and lumen mouth opening were satisfactory in LAD proximal.

We intended to use proximal part of the saphenous vein for proximal aortic anastomoses. After completion of bypasses and patch plasty procedure cross clamping was released allow the heart before beginning to beat. The patient was warmed up. After defibrillating the heart two times, normal sinusal rhythm restored. Immediately before beginning the proximal anastomosis and mean arterial pressure was $60 \mathrm{mmHg}$ on pump. Also we observed the pulsation of the LAD saphenous vein. Then we measured the saphenous vein pressure. This pressure was equal to aortic pressure. We made proximal anastomosis for right coronary artery. After these procedures we terminated to bypass but we didn't made the proximal anastomosis for LAD. We allowed the heart to beat. İt was observed that heart was contracting normally with a mean pressure $70 \mathrm{mmHg}$. Before protamine administration we compared the pressures between LAD saphenous vein and aorta. All of them we measured equal. Then we applied the bulldog clamp to saphenous vein just above the patch. After protamine administration we did not observe any problem on heart beating with clamp we continue the bleeding control the heart was functionally well. Thus we decided to tie down the saphenous vein. We made only patch plasty like a carotid endarterectomy.

Total cardiopulmonary bypass time was 100 minute and an aortic cross-clamp time of 57 minute.

The patient stayed in intensive care for 3 days. He was uneventful postoperative course. The patient was discharged on the seventh postoperative day.

It is recommended that the combination of postoperative antiplatelet and warfarin after coronary endarterectomy should be given for several months (3). As thrombogenicity increases due to endothelial damage after coronary endarterectomy, we start routine anticoagulants and antiplatelets unless there is significant hemorrhage in the early postoperative hours. Postoperative follow up 12 years. This patient followed up coronary angiography was made 10 years after the operation (Fig 3). According to 10 years angiography result LAD patch plasty was working relatively good. Patient did not have any complaints. We made coronary angiography 12 years after the operation and observed that our patch plasty was occluded but patient have still class II symptoms. He is normal in daily activity now with and $\mathrm{EF}$ value $40 \%$.

\section{DISCUSSION}

This coronary endarterectomy procedure is a challenging procedure $(7,8)$ because it increases the perioperative mortality, especially in LAD. For this reason, most surgeons perform endarterectomy if there are no other options for LAD (5).

Acceptable results of the coronary endarterectomy procedure have been reported in recent literature (6).

Despite the the advers effects of coronary endarterectomy this procedure must be kept in mind in the occluted arteries. There are two techiques in coronary endarterectomy. In closed technique, shorter arteriotomy is performed and the plaque is removed with traction. When performing endarterectomy with a closed 
technique, the plaque may break and the diagonal and septal branches branching from the LAD may not open, and there is also a risk of disruption in the proximal and distal of the LAD.

Open technique requires long incision extending into the proximal and distal part of the artery. This technique allows to lift off the plaque under vision. The incidence of intimal flap formation is low. The risk of residuel obstruction, dissection, distal myocardial ischemia is low. The open technique allows the entire atherosclerotic plaque to be removed in full block. Open coronary endarterectomy technique: It should include the branch and the branch of the LAD, it involves all your removal including the most proximal and distal of the lesion in the LAD.

This technique is not only a time consuming procedure but also carries the risk of proximal obstruction due to the unnoticed flash and the catastrophic result.

This patient tolerated this technique and no problem. Although we found this technique useful, it can not be put into daily practice especially in LAD endarterectomy.

\section{CONCLUSION}

This technique must be considered as an adjunct to coronary artery bypass grafting-coronary endarterectomy and has a significant role in achieving optimal revascularization.

\section{Declaration of conflicting interests}

The authors declared no conflicts of interest with respect to the authorship and/or publication of this article.

\section{REFERENCES}

1. Fukui T, Takanashi S, Hosoda Y. Coronary endarterectomy and stent removal in patients with in-stent restenosis. Ann Thorac Surg 2005;79:558-563.

2. Bailey CP, May A, Lewman WM. Surgical after coronary endarterectomy in man. JAMA 1957;164:6416 .

3. Fukui T,Tabata M, Taguri M, Manabe S, Morita S, Takanashi S. Extensive reconstruction of the left anterior descendin coronary artery with an internal thoracic artery graft. Ann Thorac Surg 2011;91:44551.

4. Asimakopoulos G, Taylor KM, Ratnatunga CP. Outcome of coronary endarterectomy: a case-control study. Ann Thorac Surg. 1999;67:989-93.

5. Livesay JJ, Cooley DA, Hallman GL, Reul GJ, Ott DA, Duncan JM, et al. Early and late results of coronary endarterectomy. Analysis of 3,369 patients. J Thorac Cardiovasc Surg. 1986;92(4):649-60.

6. Uchimuro T, Fukui T, Mihara W, Takanashi S. Acute thorombosis after endarterectomy of stented left anterior descending artery. Interac Cardiovasc Thorac Surg 2009;8:663-5.

7. Qureshi SA, Halim MA, Pillai R, Smith P, Yacoub MH. Endarterectomy of the left coronary system: analysis of a 10-year experience. J Thorac Cardiovasc Surg 1985;89;852-9.

8. Sundt TM, Camillo CJ, Mendeloff EN, Barner HB, Gay WA Jr. Reappraisal of coronary endarterectomy for the treatment of diffuse coronary artery disease. Ann Thorac Surg. 1999;68:1272-77.

\section{APPENDIX}



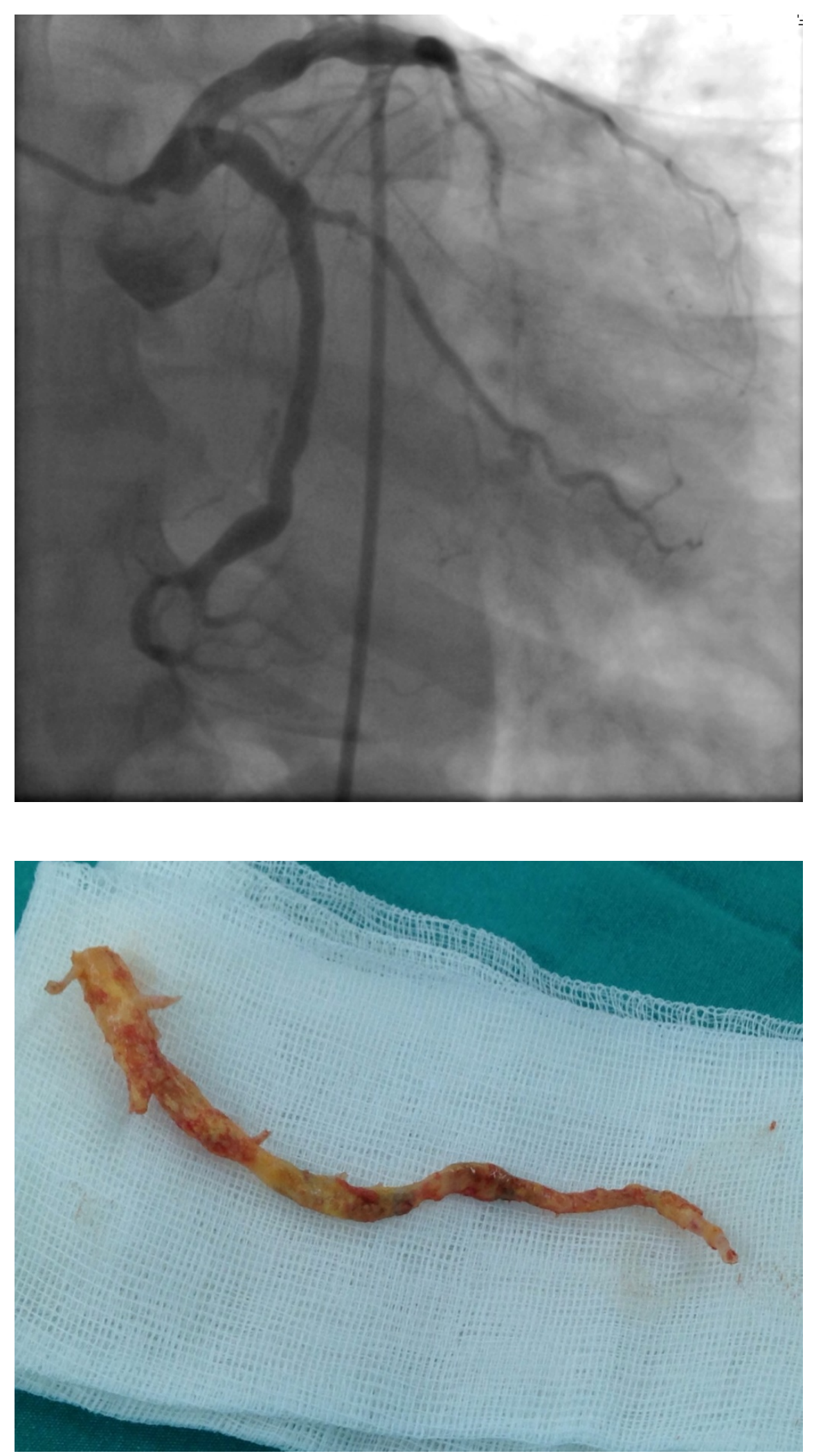


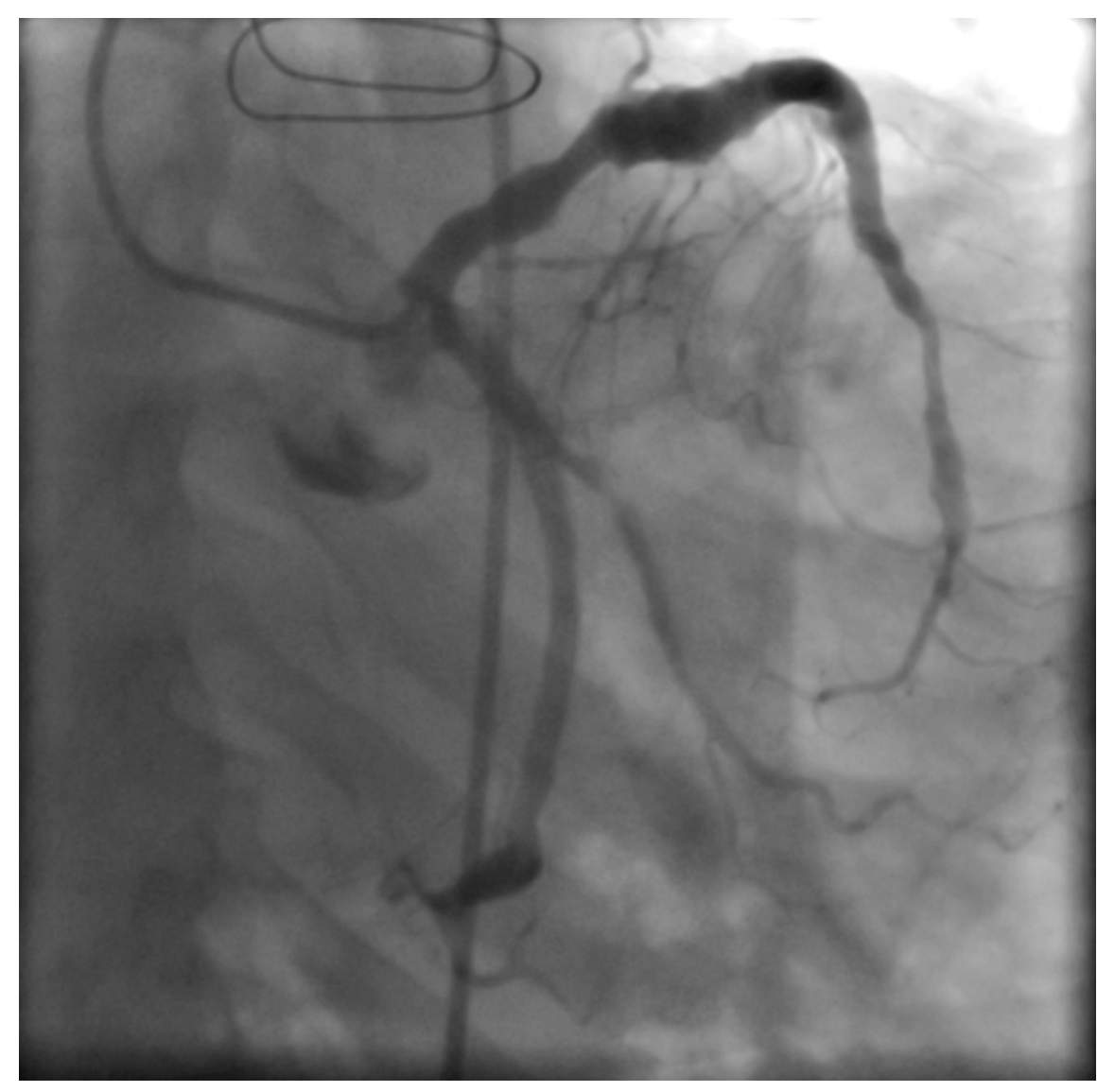



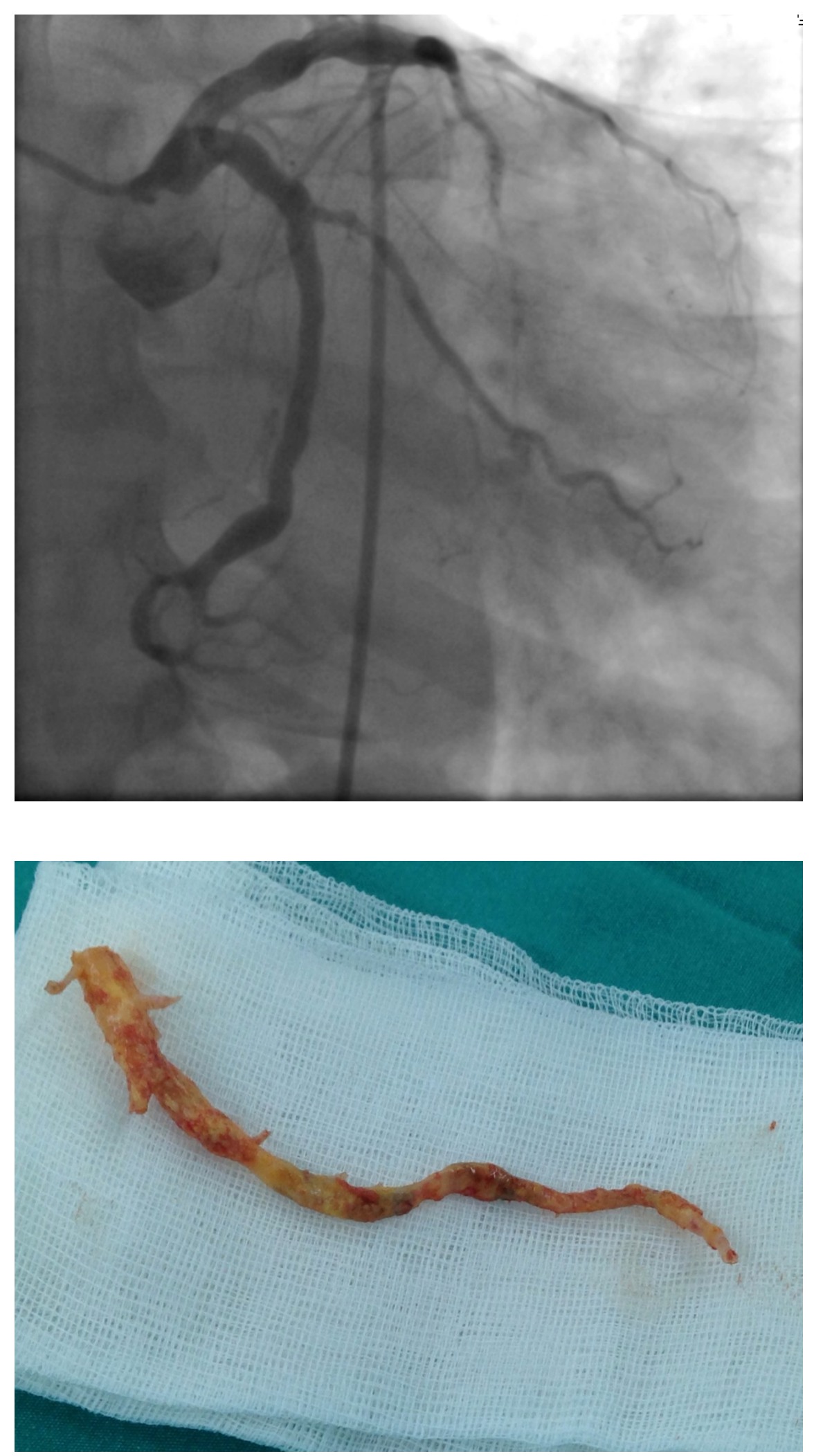


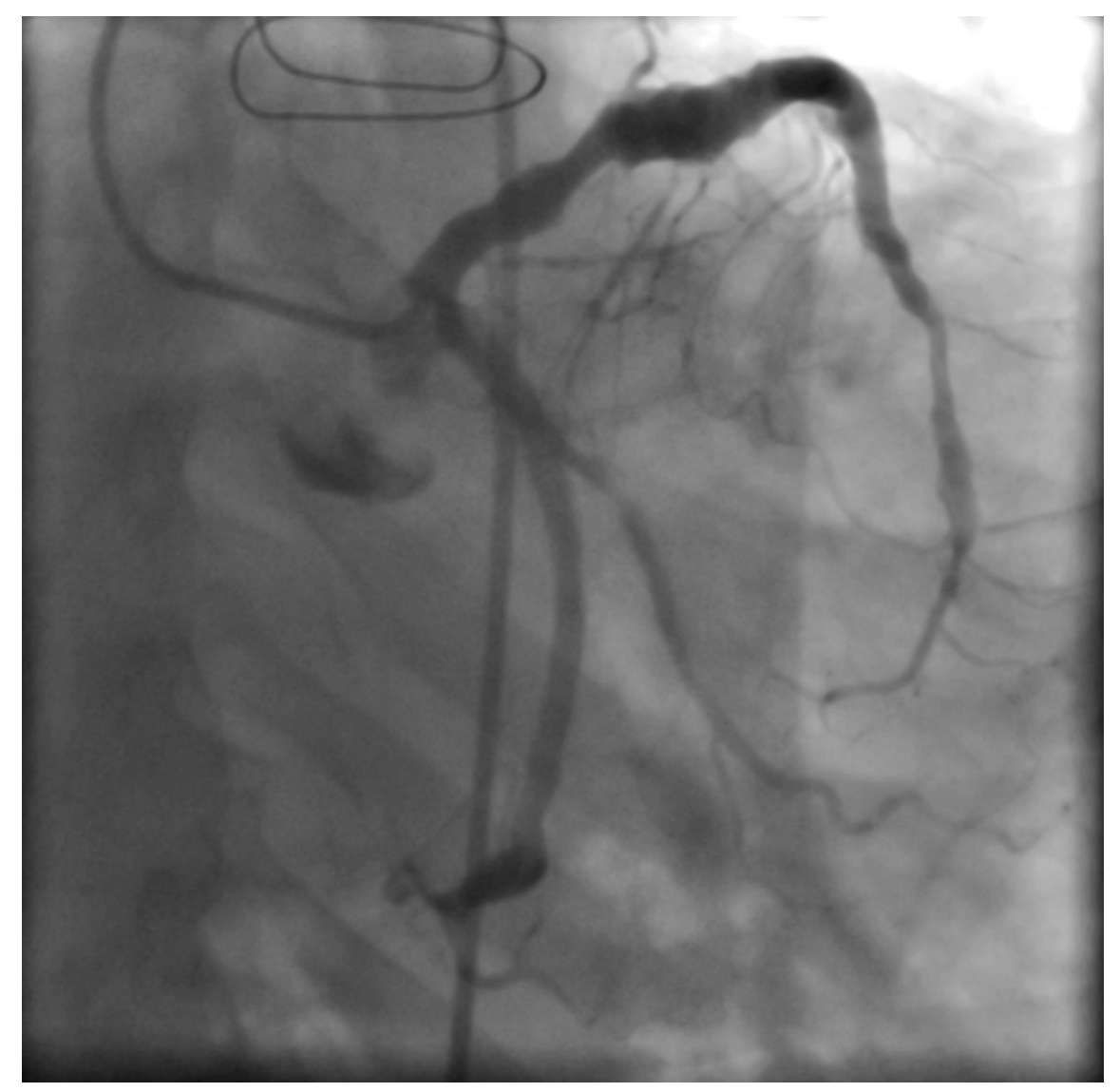

